\title{
Endoscopic Endonasal Approach for Suprasellar Lesions in Children : Complications and Prevention
}

\author{
Yong Hwy Kim, M.D., Kyu-Chang Wang, M.D., Ph.D., ${ }^{1,2}$ Ji Hoon Phi, M.D., Ph.D., ${ }^{1,2}$ Seung-Ki Kim, M.D., Ph.D. ${ }^{1,2}$ \\ Department of Neurosurgery, Seoul National University Hospital, Seoul National University College of Medicine, Seoul, Korea \\ Division of Pediatric Neurosurgery, ${ }^{2}$ Seoul National University Children's Hospital, Seoul National University College of Medicine, Seoul, Korea
}

The endoscopic endonasal approach (EEA) has been popularized in adults and has been applied to an expanding range of surgical modules and indications in this population. However, its clinical application in pediatric neurosurgery has been impeded by the differences in anatomical features and the relatively low incidence of diseases to which it is applicable. In this review article, we mainly discuss the surgical indications, feasibility, and complications of EEA for suprasellar lesions in children based on a review of the literature, focusing especially on the age-related anatomical features of the nasal cavity, various pathologic entities, and the impact of EEA on long-term craniofacial growth.

Key Words : Endoscopic endonasal surgery · Suprasellar lesions · Children · Indications · Complications.

\section{INTRODUCTION}

The ancient Egyptians were the pioneers and built the foundation of natural science, including the field of neurosurgery. The radiological evidence of skull base perforations in mummies implies that they regarded the nasal cavity as the corridor to the brain". In his book "Histories", Herodotus wrote out procedures for brain extraction excerebration that are very similar to those of modern endonasal skull base surgery ${ }^{6}$. However, the concept of approaching the brain via the nasal cavity could not been highlighted, as brain surgery itself was not established until 1900. The trans-nasal skull base approach came into the spotlight of modern medical practice with the contributions of Harvey Cushing and Oskar Hirsch in the early 1900s, although Cushing completely abandoned the trans-sphenoidal approach (TSA) in 1929 due to high surgical mortality ${ }^{24)}$. Oskar Hirsch, a Viennese otolaryngologist, introduced the endonasal route to the pituitary in $1909^{8)}$. Since then, surgical techniques have progressed toward simple, safe and minimally invasive approaches thanks to technical developments such as microscopy and fluoroscopy. Following the introduction of the endoscope as an adjunct to microscopy for extrasellar tumors in the 1970s, pure endoscopic TSA was described in the $1990 \mathrm{~s}^{2,14,15)}$. With these documented experiences, the development of various surgical instruments and technical improvements, pure endoscopic

- Received : January 19, 2017 •Revised : March 30, 2017 •Accepted : April 6, 2017

- Address for reprints : Seung-Ki Kim, M.D., Ph.D.

Department of Neurosurgery, Seoul National University Hospital, Seoul National University College of Medicine, 101 Daehak-ro, Jongno-gu, Seoul 03080, Korea Tel : +82-2-2072-3084, Fax : +82-2-744-8459, E-mail : nsthomas@snu.ac.kr

This is an Open Access article distributed under the terms of the Creative Commons Attribution Non-Commercial License (http://creativecommons.org/licenses/by-nc/4.0) which permits unrestricted non-commercial use, distribution, and reproduction in any medium, provided the original work is properly cited. 
pituitary surgery has become increasingly popular and the concept of expanded TSA was introduced ${ }^{16,18,19)}$.

The advantages of endoscopic surgery include visualization of blind spots via panoramic and angled views, with the capacity for close-up magnification. The wide visualization of surrounding anatomical landmarks helps to orient surgeons to the location of critical structures while avoiding irradiation from fluoroscopy ${ }^{8)}$. This feature is extremely useful in revision surgery for recurrent or residual tumor with distorted surgical corridors $^{13)}$. Moreover, the retractor does not restrict the space available for instrument movement, although it plays a beneficial role in protecting the nasal mucosa and as a protective barrier or compressor for bloody mucosal oozing. However, surgical manipulation under the endoscopic view is not familiar to neurosurgeons trained with microscopy, and there is a steep learning curve. The 2D images provided by the static endoscope and the consequent loss of depth perception, in contrast to the $3 \mathrm{D}$ images provided by microscopy, are troublesome for novices, although the loss of $3 \mathrm{D}$ visual perception could be overcome by the dynamic movement of endoscopic views. These features have driven changes in surgical approach trends, and favorable results have been published over the last 10 years. However, the majority of published studies on the endoscopic endonasal approach (EEA) have comprised adult cohorts, and studies of young patients are rare. This article focuses on the surgical indications, outcomes and characteristic complications of EEA in childhood, including preoperative considerations and prevention of complications.

\section{INDICATIONS}

The most common surgical indication for EEA in adults has been lesions in the sella turcica, such as pituitary adenomas and Rathke's cleft cysts, because the procedure originated from traditional TSA and the concavity of the sellar fossa is difficult to reach by transcranial methods. With the generalization of extended TSA, the sagittal extent of a tumor (i.e., whether it is located within the sella or beyond the sellar fossa) does not affect the decision regarding surgical approach, and the coronal extent of tumor has become the major concern. Kassam previously identified the medial orbital wall as the lateral anatomical boundary of EEA for the anterior fossa, in addition to the optic canal and cavernous internal carotid ar- tery (ICA) protuberance in the area of the planum sphenoidale, tuberculum sellae and sella itself ${ }^{18)}$. The paraclinoid ICA and jugular foramen limit the lateral extension of EEA in the posterior fossa ${ }^{19)}$. In other words, we could directly access the bony and dural window between the bilateral critical neurovascular structures via midline EEA, and intracranial lesions located between the bilateral cranial nerves, ICAs, and posterior communicating arteries could be operated on regardless of the pathologic entities. Considering the differences in disease prevalence with age, fibrous dysplasia, craniopharyngiomas, pituitary adenomas, sarcomas, dermoid/epidermoid cysts, chordomas, and chondrosarcomas could be selected as pathological entities for which EEA is indicated in young patients $^{27,34)}$.

With the comprehensive investigation of ventral skull base anatomy and technical advances in the accuracy of surgical navigation systems, the surgical field for EEA has been extended laterally from the midline to the paramedian skull base, and several surgical corridors have been introduced and used in practice, such as the so-called coronal module ${ }^{5)}$. These techniques are often performed via the pterygopalatine fossa, which is bounded by the maxilla anterolaterally, the pterygoid process posteriorly, and the palatine bone anteromedially. In contrast, EEA for midline lesions uses the air cells and sinuses made by the lateral lamella structures of the nasal cavity, such as the uncinate process, bulla ethmoidalis, basal lamella of the middle turbinate, and superior turbinate. The transpterygoid route can be created by a wide antrostomy of the medial maxillary wall and removal of the posterior maxillary sinus wall. The dissection of contents in the pterygopalatine fossa and identification of the vidian canal provide the key landmarks for anatomical orientation and following surgical procedures ${ }^{22)}$. A transpterygoid approach with additional procedures provides a surgical corridor to the medial petrous apex, infrapetrous area, suprapetrous area, lateral cavernous sinus, infratemporal fossa, occipital condyle and jugular foramen ${ }^{5}$. Paramedian EEA is usually indicated in cases with wide anterior tumors occupying space in the ventral skull base and is rarely used for purely intracranial tumors. Fortunately, tumors in the paramedian skull base are rare in childhood and the most common tumor pathologies for which EEA is indicated are juvenile nasopharyngeal angiofibromas, fibrous dysplasia, fibro-osseous tumors, sarcomas, and chondrosarcomas. 

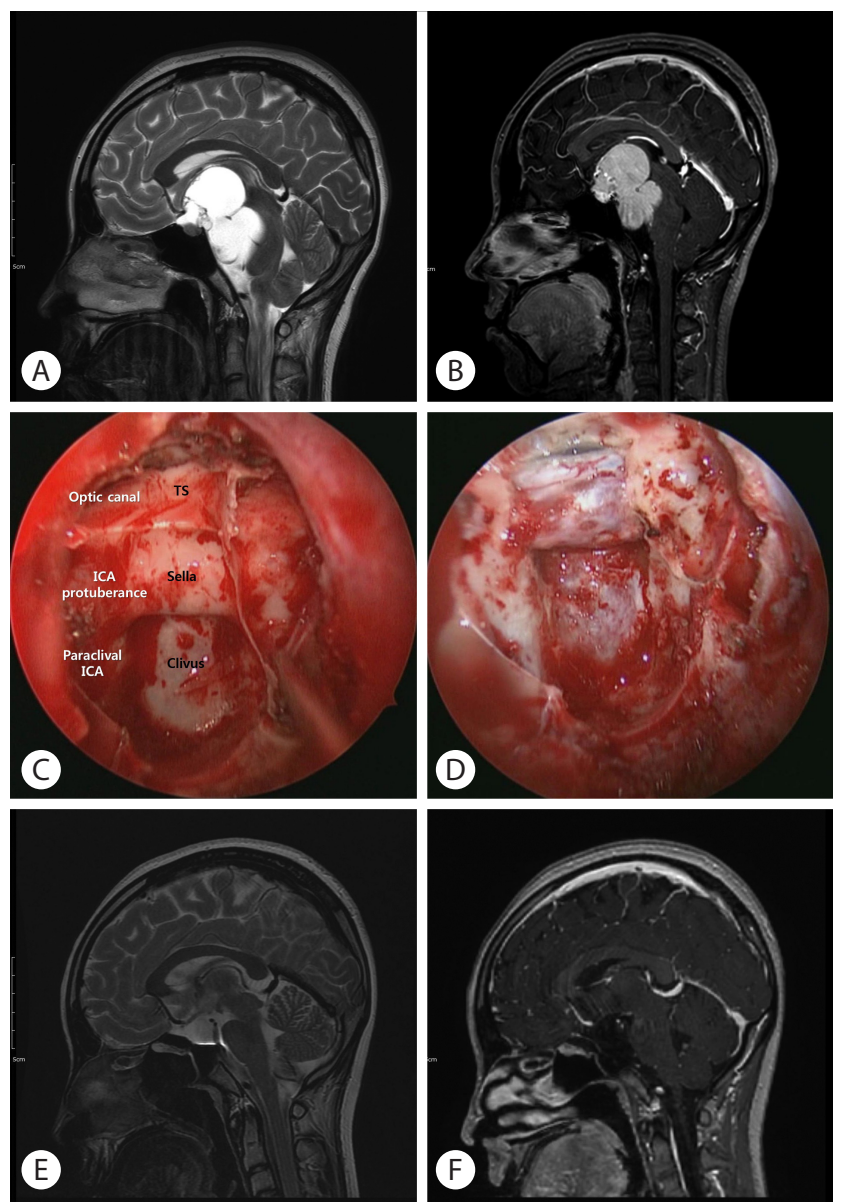

Fig. 1. A case of craniopharyngioma located in the suprasellar area and posterior fossa (A, B). The wide sphenoidotomy was performed to exposure the midline skull base bone from the tuberculum sellae to lower clivus (C). The dura was exposed after the bony work between bilateral optic canal at the level of tuberculum and bilateral internal carotid artery at the level of sella and clivus (D). The post-operative 6-months MR showed no residual tumora and parenchymal damage of normal brain. The compressed pons by the tumor showed the normal contour (E, F). TS : tuberculum sellae, ICA : internal carotid artery, MR : magnetic resonance.

In summary, EEA is indicated for central skull base tumors located between the bilateral orbital walls and optic canals in the anterior cranial fossa. The bilateral ICAs are the lateral boundaries of EEA for centrally located skull base tumors in the middle and posterior fossa (Fig. 1). The coronal modules of EEA could be useful approaches for paramedian skull base tumors, as they allow for a wide bony window at the skull base. The cases indicated for EEA are illustrated in Fig. 2.
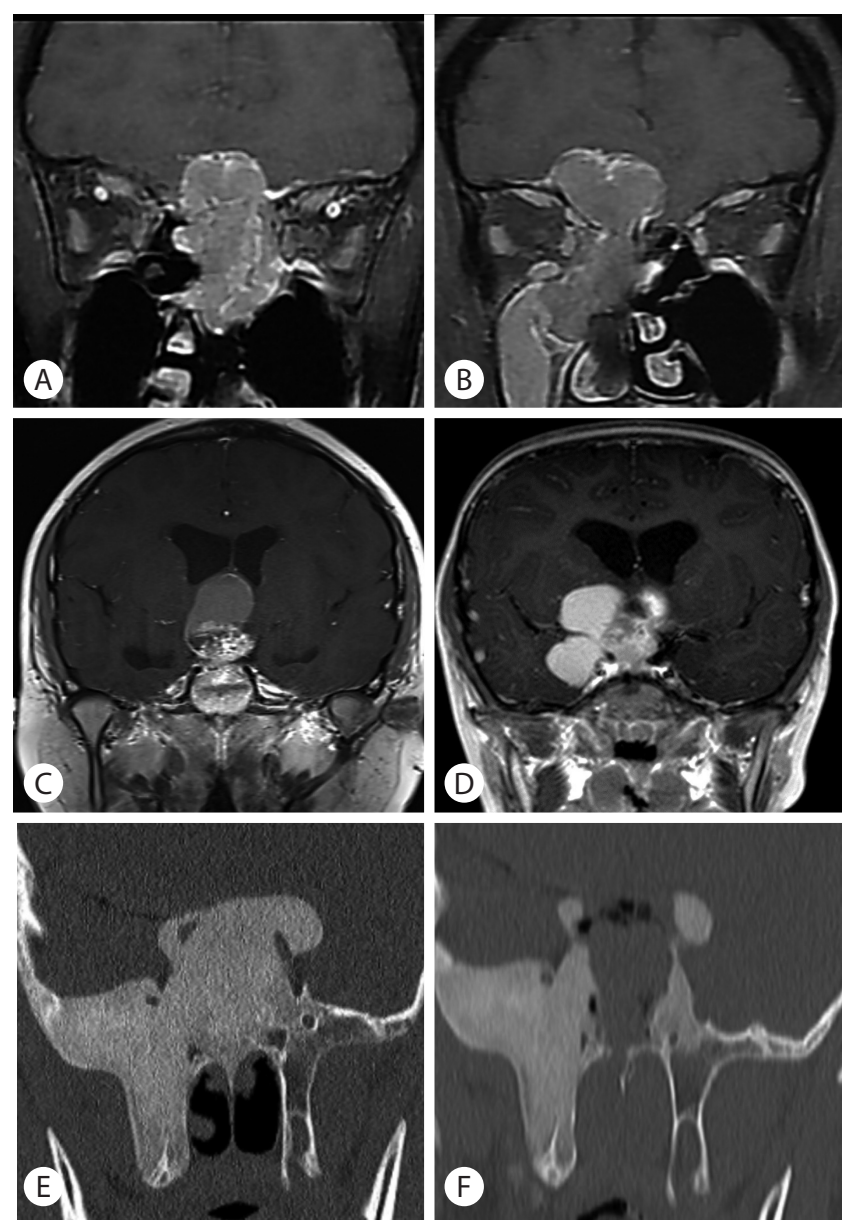

Fig. 2. Two cases of olfactory neuroblastoma with diffident extent of tumor (A, B). Endoscopic endonasal approach is indicated for the tumor within the bilateral medial orbital wall (A); however, craniofacial resection is inevitable in tumors extending beyond this region (B). In cases of craniopharyngioma, the lateral extent of tumor is the critical point in determining the surgical approach. A tumor between the bilateral internal carotid arteries is eligible for endoscopic endonasal approach even if combined with obstructive hydrocephalus (C), but, a tumor extending beyond the internal carotid artery bifurcation would be better treated via transcranial approaches (D). Fibrous dysplasia involving the optic canal could be managed via Endoscopic endonasal approach. Pre- (E) and postoperative (F) coronal computed tomography images show the decompressed bilateral optic canals.

\section{PRACTICAL CONSIDERATIONS FOR EEA IN CHILDHOOD}

\section{Developing nasal structures and skull base}

EEA in pediatric patients requires entry into the immature nasal cavity and sphenoid sinus through the developing splanchnocranium. Therefore, anatomical boundaries based 
on the exact age-related differences in midline skull base anatomy play a critical role. Tatreau et al. ${ }^{32}$ measured important anatomical data about key structures in EEA based on computed tomography (CT) scans. First, the anterior nasal cavity is the point of entry for EEA and the distance between the bilateral piriform apertures, which are the most superficial bony structures, is the determining factor of the width of the anterior aperture of the nose because the surrounding soft tissue such as the nasal ala can be retracted to facilitate the entrance of the endoscope and instruments. The pyriform aperture width was significantly narrower in patients up to 6 to 7 years of age $(17.2 \pm 0.5 \mathrm{~mm})$ compared to adults $(22.2 \pm 1.3 \mathrm{~mm})$. However, there was no significant difference in pyriform aperture width among patients 9 to 10 years of age and older. The second concern is sphenoid sinus pneumatization, although the accuracy of neurosurgical navigation and advances in drill technology have made this concern less clinically significant. Pneumatization of the anterior wall of the sphenoid sinus is not fully completed until 6 to 7 years of age, and it then progresses posteriorly to the planum sphenoidale and anterior sellar wall. At 6 to 7 years old, pneumatization of the anterior sellar wall and the sellar floor was complete in $77 \%$ and $32 \%$ of patients, respectively. Pneumatization did not occur before 10 years of age in the clival recess but it reached the anterior clivus at 15 years of age. The last concern is the intercarotid distance, which determines the width of the skull base corridor for transtubercular and sellar approaches. The cavernous intercarotid distance was not significantly different between patients 9 to 10 years of age and adults $(12.6 \pm 0.9)$, although it was significantly shorter in patients $<24$ months old $(8.8 \pm 1.2 \mathrm{~mm})$ than in those up to 6 to 7 years old $(10.2 \pm 1.0$ $\mathrm{mm}$ ). Interestingly, intercarotid distance at the level of the superior clivus did not change after 24 months of age, although bony prominences of the clival carotid arteries are clearly associated with age. This report showed that, compared to adults, the development of critical nasal structures affecting EEA was $80-90 \%$ completed by the age of 8 years and that caution should be taken in patients under 3 to 4 years old due to the narrow aperture and intercarotid distance.

Knowledge of the anatomic location of sinonasal and skull base growth centers is important because disturbance of these centers can impair long-term craniofacial growth ${ }^{27)}$. Compared with transcranial approaches, EEA does not require surgical manipulation of cranial vaults, but it is necessary to perform a relatively wide resection of the skull base sometimes. The growth of the calvaria and skull base is quite different. The growth of the cranial vault grows is rapid and driven primarily by the volume of neural tissue, whereas growth of the skull base is slow and partially independent of neural tissue. For example, frontal lobe growth slows between 5 and 6 years of age, but the anterior fossa and nasomaxillary complex continue to be drawn anteriorly for 3-4 more years because of middle fossa expansion ${ }^{10)}$. Sgouros et al. ${ }^{28)}$ showed that skull base growth is uniform until the age of 5 years and a change in the growth rate typically occurs after that age. Gruber and Brockmeyer ${ }^{10)}$ showed that the skull base of children remains underdeveloped for at least 10 years after birth and the spheno-occipital synchondrosis, one of the primary skull base growth centers, closes at the completion of skull base ossification, around age 12 to 16 years ${ }^{10,28)}$.

Therefore, it is the policy of the authors' institution that EEA be recommended to patients 8 years or older, keeping in mind the surgical space and long-term impact on craniofacial growth such as underdevelopment of central facial bones.

\section{Skillful surgical technique}

The learning curve of EEA, attributable to differences in surgical visualization, long surgical corridor, complex anatomy and different instrumentation, is well known. A stepwise progression, starting with mastering the more straightforward procedures before attempting more complicated approaches, has been recommended for surgical teams ${ }^{31}$. Extensive practice and experience are required to execute these types of surgeries and it has been well established that the rates of favorable outcomes and complications in EEA are largely dependent on surgical skill and experience. However, the representative tumors for which EEA is indicated in pediatric patients, such as craniopharyngiomas and pituitary adenomas, are relatively infrequent; this is one of the main causes of the prolonged learning curve, similar to transcranial skull base surgeries ${ }^{1}$. Epidemiologic studies have shown that the age-adjusted incidence rate of tumors in the sellar region varies from 3.68 per 100000 to 0.78 per 100000 between ages 0 to $19^{26)}$. Zhan et al. ${ }^{35)}$ recently described a surgical retrospective cohort of 11 pediatric sellar tumors over 2 years and Chivukula et al. published an EEA series of only 133 patients (including 21 skull base bony lesions) who underwent surgery at the University of Pittsburgh Medical Center over 13 years ${ }^{4)}$. A multidisci- 
plinary team approach including various specialists with different backgrounds in a collaborative environment has been recommended to establish the safety and feasibility of surgery and shorten the duration of the learning curve ${ }^{30}$. Stepwise progression, starting and mastering the more simple procedures before attempting more complicated procedures, has been recommended ${ }^{31}$.

\section{Surgical instruments for EEA}

Several instruments are required for the endoscopic skull base surgery, which are unique for transnasal approach or different design with those for transcranial approach. The endoscope of $4 \mathrm{~mm}$ diameter and $18 \mathrm{~cm}$ length is the most popularly adopted optic devices in the endoscopic skull base surgery, regardless of the age. The endoscope of $2 \mathrm{~mm}$ diameter could be used in young patients with the very narrow nasal cavity, however, its quality of visualization is not as high as it from larger one. In the nasal cavity manipulation, the microdebrider is the useful device to remove the unnecessary mucosa in the sphenoid sinus. The deliate bony work around the carotid protuberance and optic canal is performed with the diamond burrs with long and fine handpiece. The microsurgical instruments are modified to be suitable for the long and narrow surgical corridor of nasal cavity. The microdissectors with long shaft and the gun type of scissor, microforceps and bipolar forceps are popularly adopted. In addition, the angled suction are valuable devices in order to manipulate the skull base bony window.

\section{COMPLICATIONS AND PREVENTION}

Potential complications of EEA vary, including those related to sinonasal dysfunction, neurovascular injury, cerebrospinal fluid (CSF) leak, central nervous system (CNS) infection, and damage to CNS tissue ${ }^{20)}$. The causes and recommendations for prevention of neurovascular complications such as hemorrhagic accident, infarction, and cranial neuropathy or direct CNS damage (e.g., hypothalamic damage in craniopharyngioma) are not so different between EEA and transcranial surgery. A comprehensive understanding of distorted anatomy and tumor characteristics, securing a wide and clean surgical field, proper fine microsurgical dissection and manipulation, and meticulous bleeding control are the keys to avoiding and preventing these surgical complications.

\section{Sinonasal complications}

Short-term sinonasal dysfunction includes epistaxis, sensation of nasal blockage due to mucosal swelling and crusting in the nasal cavity. One study showed that patients treated with the endoscopic technique were more likely to have postoperative nasal debridement compared with those who underwent microscopic surgery ${ }^{23)}$. Sinonasal function worsened substantially for both groups at 2 weeks after surgery, but then returned to baseline at 3 months. At 3 months after surgery, patients treated with EEA reported statistically better sinonasal quality of life compared with patients treated by microscopic techniques. Experiences from the Massachusetts General Hospital show that chronic rhinosinusitis was the most common delayed complication $^{25)}$. Synechiae, septal perforation, and altered olfaction are also possible long-term complications. These can be prevented and managed by minimally invasive surgical manipulation of nasal structures, preservation of the upper septal mucosa, scheduled debridement and saline irrigation, and modification of surgical approach ${ }^{12,21)}$.

\section{Hemostasis and bleeding control}

Clear surgical visualization with proper control of bleeding is essential to achieve surgical goals and prevent avoidable complications. The robust vascularity created by the tight vascular network of the nasal cavity leads to diffuse oozing over the course of the operation. Low-pressure bleeding can be easily controlled by lowering blood pressure, gentle compression, hemostatic agents, electrocautery, and warm saline irriga$\operatorname{tion}^{17)}$. However, high-flow arterial bleeding often requires direct electrocautery or ligation with surgical clips and demands dynamic movement of the endoscope for the direct visualization of the bleeding focus and a team approach to control it ${ }^{27}$. ICA injury is the most catastrophic complication of EEA and in-depth anatomic knowledge and proper surgical technique are paramount to prevent it. The most commonly injured ICA segment was the cavernous, followed by the ophthalmic; this could occur at various surgical steps ${ }^{3}$. ICA injuries can sometimes be repaired but often require nasal packing and endovascular sacrifice ${ }^{3,9,20)}$. Valentine et al. performed animal model experiments to compare the efficacy of packed material in ICA injury. They randomized sheep to receive 1 of 5 hemostatic techniques (Floseal, oxidized regenerated cellulose, Chi- 
tosan gel, muscle patch, or the U-Clip anastomotic device) and measured the time to hemostasis, time of sustained proper blood pressure, amount of blood loss, and survival time. This study revealed that the muscle patch and U-Clip anastomotic device significantly improve survival, reduce blood loss, and achieve primary hemostasis while maintaining vascular patency $^{33)}$.

\section{CSF leakage and infection}

CSF leakage and the associated infections are the Achilles' heel of EEA and affected by various factors such as body-mass index, tumor characteristics, extent of exposure and the reconstructive techniques used. The skull base reconstruction techniques required in EEA are quite different from those used in trans-sellar approaches due to the degree of CSF leakage flow. Among the various surgical techniques, the nasoseptal flap (NSF) has become the workhorse for skull base reconstruction after endoscopic endonasal surgery, after it was first described by Hadad in $2006^{11)}$. The maximal possible size of an NSF depends on the size of the nasal septum, and it should be an important consideration with pediatric patients. A study with CT scans suggests that, although the width of the NSF is likely sufficient at any age, the length may be insufficient for a trans-sellar/transplanar defect until age 6 to 7 years, a transcribriform defect until age 9 to 10 years, and insufficient for a clival defect at all pediatric ages ${ }^{27,29)}$. Therefore, adjuvant solutions including a free graft, turbinate flap, galeal flap, or temporalis rotation flap should be considered in young patients or revision surgery.

\section{CONCLUSION}

EEA has expanded its surgical modules and indications based on documented evidence during the last two decades. Recent favorable results have made EEA popular in pediatric patients, although its introduction was later than in adulthood due to differences in prevalence of pathologies, a narrow surgical corridor, and concerns regarding the growing features of the skull base. However, several points, including long-term tumor control and impact on craniofacial growth, should be elucidated in studies with larger samples and longer follow-up periods.

\section{- Acknowledgments}

This research was supported by a grant from the Korea Health Technology R\&D Project through the Korea Health Industry Development Institute (KHIDI), funded by the Ministry of Health \& Welfare, Republic of Korea (grant number: HI12C0066; to Kim SK and HI16C-1111-020016 to Kim YH).

\section{References}

1. Bunin GR, Surawicz TS, Witman PA, Preston-Martin S, Davis F, Bruner $\mathrm{JM}$ : The descriptive epidemiology of craniopharyngioma. J Neurosurg 89 : 547-551, 1998

2. Cappabianca P, Alfieri A, de Divitiis E : Endoscopic endonasal transsphenoidal approach to the sella: towards functional endoscopic pituitary surgery (FEPS). Minim Invasive Neurosurg 41 : 66-73, 1998

3. Chin OY, Ghosh R, Fang CH, Baredes S, Liu JK, Eloy JA : Internal carotid artery injury in endoscopic endonasal surgery: a systematic review. Laryngoscope $126: 582-590,2016$

4. Chivukula S, Koutourousiou M, Snyderman CH, Fernandez-Miranda JC, Gardner PA, Tyler-Kabara EC : Endoscopic endonasal skull base surgery in the pediatric population. J Neurosurg Pediatr 11 : 227-241, 2013

5. de Lara D, Ditzel Filho LF, Prevedello DM, Carrau RL, Kasemsiri P, Otto $B A$, et al. : Endonasal endoscopic approaches to the paramedian skull base. World Neurosurg 82(6 Suppl) : S121-S129, 2014

6. Elhadi AM, Kalb S, Perez-Orribo L, Little AS, Spetzler RF, Preul MC : The journey of discovering skull base anatomy in ancient Egypt and the special influence of Alexandria. Neurosurg Focus 33 : E2, 2012

7. Fanous AA, Couldwell WT : Transnasal excerebration surgery in ancient Egypt. J Neurosurg 116 : 743-748, 2012

8. Gandhi CD, Christiano LD, Eloy JA, Prestigiacomo CJ, Post KD : The historical evolution of transsphenoidal surgery: facilitation by technological advances. Neurosurg Focus 27 : E8, 2009

9. Gardner PA, Tormenti MJ, Pant H, Fernandez-Miranda JC, Snyderman $\mathrm{CH}$, Horowitz MB : Carotid artery injury during endoscopic endonasal skull base surgery: incidence and outcomes. Neurosurgery 73(2 Suppl Operative) : ons261-269; discussion ons269-ons270, 2013

10. Gruber DP, Brockmeyer D : Pediatric skull base surgery. 1. Embryology and developmental anatomy. Pediatr Neurosurg 38 : 2-8, 2003

11. Hadad G, Bassagasteguy L, Carrau RL, Mataza JC, Kassam A, Snyderman $\mathrm{CH}$, et al. : A novel reconstructive technique after endoscopic expanded endonasal approaches: vascular pedicle nasoseptal flap. Laryngoscope 116 : 1882-1886, 2006

12. Hong SD, Nam DH, Kong DS, Kim HY, Chung SK, Dhong HJ : Endoscopic modified transseptal transsphenoidal approach for maximal preservation of sinonasal quality of life and olfaction. World Neurosurg 87 : 162169, 2016

13. Hwang JM, Kim YH, Kim JW, Kim DG, Jung HW, Chung YS : Feasibility of endoscopic endonasal approach for recurrent pituitary adenomas after 
microscopic trans-sphenoidal approach. J Korean Neurosurg Soc 54 : 317-322, 2013

14. Jankowski R, Auque J, Simon C, Marchal JC, Hepner H, Wayoff M : Endoscopic pituitary tumor surgery. Laryngoscope 102 : 198-202, 1992

15. Jho HD, Carrau RL, Ko Y, Daly MA : Endoscopic pituitary surgery: an early experience. Surg Neurol 47 : 213-222; discussion 222-213, 1997

16. Kaptain GJ, Vincent DA, Sheehan JP, Laws ER Jr : Transsphenoidal approaches for the extracapsular resection of midline suprasellar and anterior cranial base lesions. Neurosurgery 49 : 94-100; discussion 100101, 2001

17. Kassam A, Snyderman CH, Carrau RL, Gardner P, Mintz A : Endoneurosurgical hemostasis techniques: lessons learned from 400 cases. Neurosurg Focus $19: \mathrm{E} 7,2005$

18. Kassam A, Snyderman CH, Mintz A, Gardner P, Carrau RL : Expanded endonasal approach: the rostrocaudal axis. Part I. Crista galli to the sella turcica. Neurosurg Focus 19 : E3, 2005

19. Kassam A, Snyderman CH, Mintz A, Gardner P, Carrau RL : Expanded endonasal approach: the rostrocaudal axis. Part II. Posterior clinoids to the foramen magnum. Neurosurg Focus 19 : E4, 2005

20. Kassam AB, Prevedello DM, Carrau RL, Snyderman CH, Thomas A, Gardner $P$, et al. : Endoscopic endonasal skull base surgery: analysis of complications in the authors' initial 800 patients. J Neurosurg 114 : 1544-1568, 2011

21. Kassam AB, Thomas A, Carrau RL, Snyderman CH, Vescan A, Prevedello $D$, et al. : Endoscopic reconstruction of the cranial base using a pedicled nasoseptal flap. Neurosurgery 63(1 Suppl 1) : ONS44-ONS52; discussion ONS52-ONS53, 2008

22. Kassam $A B$, Vescan $A D$, Carrau RL, Prevedello DM, Gardner P, Mintz $A H$, et al. : Expanded endonasal approach: vidian canal as a landmark to the petrous internal carotid artery. J Neurosurg 108 : 177-183, 2008

23. Little AS, Kelly DF, Milligan J, Griffiths C, Prevedello DM, Carrau RL, et al. : Comparison of sinonasal quality of life and health status in patients undergoing microscopic and endoscopic transsphenoidal surgery for pituitary lesions: a prospective cohort study. J Neurosurg 123 : 799807,2015
24. Liu JK, Cohen-Gadol AA, Laws ER Jr, Cole CD, Kan P, Couldwell WT : Harvey Cushing and Oskar Hirsch: early forefathers of modern transsphenoidal surgery. J Neurosurg 103 : 1096-1104, 2005

25. Naunheim MR, Sedaghat AR, Lin DT, Bleier BS, Holbrook EH, Curry WT, et al. : Immediate and delayed complications following endoscopic skull base surgery. J Neurol Surg B Skull Base 76 : 390-396, 2015

26. Ostrom QT, Gittleman H, Fulop J, Liu M, Blanda R, Kromer C, et al. : CBTRUS statistical report: primary brain and central nervous system tumors diagnosed in the United States in 2008-2012. Neuro Oncol 17 Suppl 4 : iv1-iv62, 2015

27. Rastatter JC, Snyderman CH, Gardner PA, Alden TD, Tyler-Kabara E : Endoscopic endonasal surgery for sinonasal and skull base lesions in the pediatric population. Otolaryngol Clin North Am 48 : 79-99, 2015

28. Sgouros S, Natarajan K, Hockley AD, Goldin JH, Wake M : Skull base growth in childhood. Pediatr Neurosurg 31 : 259-268, 1999

29. Shah MV, Haines SJ : Pediatric skull, skull base, and meningeal tumors. Neurosurg Clin N Am 3 : 893-924, 1992

30. Sindwani R, Woodard TD, Recinos PF : Building a successful endoscopic skull base and pituitary surgery practice. Otolaryngol Clin North Am $49: 1-8,2016$

31. Snyderman C, Kassam A, Carrau R, Mintz A, Gardner P, Prevedello DM : Acquisition of surgical skills for endonasal skull base surgery: a training program. Laryngoscope 117 : 699-705, 2007

32. Tatreau JR, Patel MR, Shah RN, McKinney KA, Wheless SA, Senior BA, et al. : Anatomical considerations for endoscopic endonasal skull base surgery in pediatric patients. Laryngoscope $120:$ 1730-1737, 2010

33. Valentine R, Boase S, Jervis-Bardy J, Dones Cabral JD, Robinson S, Wormald PJ : The efficacy of hemostatic techniques in the sheep model of carotid artery injury. Int Forum Allergy Rhinol 1 : 118-122, 2011

34. Venkatramani R, Pan H, Furman WL, Marron JM, Haduong J, FriedrichMedina $\mathrm{P}$, et al. : Multimodality treatment of pediatric esthesioneuroblastoma. Pediatr Blood Cancer 63 : 465-470, 2016

35. Zhan R, Xin T, Li X, Li W, Li X : Endonasal endoscopic transsphenoidal approach to lesions of the sellar region in pediatric patients. J Craniofac Surg 26 : 1818-1822, 2015 